\title{
Pathways from witnessing community violence to mental health problems among South African adolescents
}

\author{
G Donenberg, ${ }^{1,2,3} \mathrm{PhD}$; P Naidoo, ${ }^{4} \mathrm{PhD}$; A Kendall, ${ }^{1} \mathrm{PhD}$; E Emerson, ${ }^{1} \mathrm{MA}$; C L Ward, $\mathrm{PhD}$; A Kagee, ${ }^{6} \mathrm{PhD}$; L Simbayi, ${ }^{7} \mathrm{PhD}$; \\ R Vermaak, ${ }^{8} \mathrm{MA} ;$ A North, ${ }^{7} \mathrm{MA} ; \mathrm{J}$ Mthembu, ${ }^{7} \mathrm{PhD} ; \mathrm{M}$ E Mackesy-Amiti, ${ }^{9} \mathrm{PhD}$ \\ ${ }^{1}$ Center for Dissemination and Implementation Science, University of Illinois at Chicago, USA \\ ${ }^{2}$ Department of Medicine, University of Illinois at Chicago, USA \\ ${ }^{3}$ Healthy Youths Program, Department of Medicine, University of Illinois at Chicago, USA \\ ${ }^{4}$ Faculty of Medicine and Health Sciences, University of the Western Cape, Cape Town, South Africa \\ ${ }^{5}$ Department of Psychology, Faculty of Humanities, University of Cape Town, South Africa \\ ${ }^{6}$ Department of Psychology, Faculty of Arts and Social Sciences, Stellenbosch University, South Africa \\ ${ }^{7}$ Human Sciences Research Council, Cape Town, South Africa \\ ${ }^{8}$ Health Systems Trust, Cape Town, South Africa \\ ${ }^{9}$ Community Outreach Intervention Projects, School of Public Health, University of Illinois at Chicago, USA
}

Corresponding author: G R Donenberg (gerid@uic.edu)

\begin{abstract}
Background. The intersection of violence exposure and mental health problems is a public health crisis for South African (SA) adolescents. Understanding the impact of community violence on adolescent mental health can inform future interventions.

Objectives. To assess pathways between community violence exposure and internalising and externalising problems in SA adolescents receiving mental healthcare, and the roles of parent and peer relationships in these associations.

Methods. Participants ( $N=120$ parent-adolescent pairs) were recruited from four mental health clinics in Western Cape Province to participate in a pilot test of a family-based HIV prevention study. Adolescents reported on their exposure to community violence, parental attachment, peer support of risk behaviour, and mental health. Parents reported on adolescents' internalising and externalising mental health problems. Participants received transport money (ZAR30 = USD3) and a shopping voucher or cash (ZAR50 = USD5) for their time. Results. Adolescents were 12 - 18 years old (mean (standard deviation) 14.39 (1.82) years), 53\% were male, and 67\% and 33\% reported black African and mixed-race ethnicity, respectively. Parents were $94 \%$ female and reported an average monthly income of ZAR3 973 (USD397). Boys reported significantly higher rates of witnessing community violence than girls. Among boys, significant paths emerged from community violence and low parent attachment to externalising symptoms and from community violence to peer support of risky behaviour. For girls, the only significant path was from low parent attachment to peer support of risky behaviour.

Conclusions. This cross-sectional study sheds new light on the possible pathways from witnessing community violence to mental health problems among SA adolescents. Identifying factors that drive and mitigate psychological distress in the context of persistent community violence is critical to SA's future and can inform the selection and delivery of appropriate and targeted evidence-based interventions.
\end{abstract}

S Afr Med J 2020;110(2):145-153. https://doi.org/10.7196/SAMJ.2020.v110i2.13929

Young people are outpacing the growth of all other age groups in southern Africa, ${ }^{[1,2]}$ but South African (SA) adolescents face significant barriers to long-term health and productivity owing to the intersection of community violence exposure, mental illness and economic inequalities. South Africans suffer one of the highest rates of violence in the world, particularly in poorer areas, with a homicide rate five times the world average, ${ }^{[3]}$ and nearly one-third of the population is estimated to suffer from mental illness at some point in their lifetime. ${ }^{[4]}$ Witnessing violence leads to a variety of adverse mental health outcomes, and individuals with poorer mental health are more likely to witness and perpetrate violence. ${ }^{[-7]}$ The intersection of violence exposure and mental health problems therefore represents a public health crisis for SA. As the burgeoning population of adolescents transitions to adulthood, mitigating the impact of violence exposure on mental health and wellbeing is critical to the country's future stability.

Rates of violence in SA are rising. 2016 saw a 5\% increase in homicides, sexual offences climbed to 142 per day that same year, and assaults, carjackings, robberies and burglaries were at an all-time high ${ }^{[8]}$ Community violence across SA is widespread, ${ }^{[9]}$ but Western Cape Province suffers disproportionately from gang violence ${ }^{[10]}$ and homicide among 15 - 19-year-olds. ${ }^{[1]}$ According to adolescent reports, almost $70 \%$ witnessed or were victims of violence, ${ }^{[12]}$ and 33 $40 \%$ saw someone killed or a dead body in their neighborhood. ${ }^{[3,13]}$ Polyvictimisation, the experience of multiple types of violence simultaneously, is normative in SA. ${ }^{[14]}$

Exposure to persistent community violence has long-term implications for South Africans' future mental health. ${ }^{[15]}$ Global estimates indicate that $10-20 \%$ of adolescents experience mental health conditions. ${ }^{[16]}$ However, rates among SA adolescents are considerably higher $(15-41 \%),{ }^{[17-19]}$ and violence exposure is implicated in these estimates. ${ }^{[20]}$ Community violence exposure is associated with elevated rates of mental health symptoms in the USA and $S A,{ }^{[13,21,22]}$ and youth in mental healthcare report high rates of violence exposure. ${ }^{[23]}$ However, few studies have examined the links between community violence exposure and psychological outcomes for youth receiving mental health services, a unique subgroup at potentially high risk for poor long-term outcomes. Rather, most 
studies have been conducted with schoolbased, ${ }^{[24-26]}$ community-based ${ }^{[27,28]}$ and/or convenience samples ${ }^{[20,29]}$ in North America, Europe and SA, and these findings may not generalise to young people seeking mental health treatment. Importantly, teens receiving mental health services may be more accessible to interventions because they are already engaged in care.

The impact of violence exposure and trauma on psychological health may be especially salient during adolescence, a period associated with increased vulnerability to the onset of psychopathology. ${ }^{[30}$ Adolescence is a critical period of psychosocial development during which teens are developing skills to regulate emotions, navigate complex social situations, ${ }^{[31]}$ and adapt to changing relationships with peers and parents. The negative impact of violence exposure on psychological functioning may be amplified during adolescence v. other developmental periods, because teens are adopting strategies to cope with stress, and violence exposure may interfere with key milestones necessary for psychosocial development. ${ }^{[32]}$

The pervasiveness of violence in SA may have unique implications for SA adolescents' mental health. Many studies report on North American populations (e.g. Noll et al., ${ }^{[33]}$ the Institute of Medicine ${ }^{[34]}$ and Widom et al. ${ }^{[35]}$, where violence exposure is more discrete and less ubiquitous, or on SA school- and community-based samples where mental health problems have not been severe enough to warrant services. Similarly, research in Western countries often focuses on violence within the home or family, such as child maltreatment or domestic violence, and its impact on child mental health outcomes. While these data document the impact of violence in known spaces and at specific times (e.g. when youth are home), the exposure to community violence and polyvictimisation typical in SA presents a near-constant threat. ${ }^{[36]}$ Unrelenting danger and multiple simultaneous violence exposures may affect mental health outcomes differently, as youth are more likely to be continuously on the alert for an assault. ${ }^{[37]}$

The present study evaluated a path model of cross-sectional data (Fig. 1) based on the Social Personal Framework ${ }^{[38]}$ (SPF) to elucidate the pathways from community violence exposure to mental health for SA adolescents receiving mental health services. The SPF was originally developed to explain high-risk behaviour among US youth in psychiatric care and has been applied broadly in both basic ${ }^{[39,40]}$ and intervention studies. ${ }^{[41-43]}$ Supported by prior research, ${ }^{[39,44]}$ the SPF proposes directional relations among environmental (e.g. crime), individual (e.g. youth mental health) and social (e.g. family functioning, peer influence) factors associated with adolescent health behaviours.

Consistent with the SPF, prior research supports a pathway from violence exposure to mental ill health depending on the type of mental health problem and violence exposure. ${ }^{[32,45,46]}$ Studies of Western and school-based samples link violence exposure to depression and anxiety, ${ }^{[32,47-51]}$ whereas a meta-analysis of 26 peer-reviewed journal articles from 1997 to 2007 concluded that externalising problems (e.g. delinquency, violence perpetration, antisocial behaviour, hostility, aggression) were more strongly and consistently associated with chronic violence exposure than were internalising problems (e.g. anxiety, depression). ${ }^{[49,52,53]}$ Understanding the divergent pathways to different mental health problems for treatment-seeking SA youth is important for selecting and delivering targeted evidencebased interventions. Based on these data, we hypothesised a direct positive relationship between community violence exposure and adolescent mental health problems, but we expected a stronger association with adolescent externalising than internalising problems (Fig. 1).

Prior research based on the SPF indicates that peers both exacerbate (negative peer influences) and mitigate (positive peer influences) adolescent stress and negative health outcomes. ${ }^{[40,54]}$ Negative peer influence has been associated with increased violence exposure $^{[55]}$ and elevated adolescent externalising problems. ${ }^{[56]}$ However, findings stem from mostly Western samples and it is unclear whether they extend to SA teens, where community violence exposure is pervasive. Understanding whether peers offset or exacerbate the impact of community violence exposure on adolescent mental health problems could inform therapeutic strategies that help teens identify and strengthen positive peer linkages. ${ }^{[57]}$ Accordingly, we expected a positive cross-sectional relationship between community violence exposure and negative peer influences, and a positive cross-sectional association between negative peer influences and increased adolescent mental health problems (Fig. 1).

Numerous US-based studies underscore the protective effects of parental acceptance, warmth and monitoring in relation to reduced adolescent externalising and internalising problems, ${ }^{[58-60]}$ particularly for girls. ${ }^{[61]}$ Positive parenting may diminish the likelihood that youth will associate with high-risk peers, ${ }^{[44]}$ offering protection against negative outside influences. In contrast, poor parental attachment is related to increased externalising problems ${ }^{[62,63]}$ and association with negative peers, and harsh parental control and permissive parenting are associated with poor adolescent mental health. ${ }^{[64]}$ These patterns, however, may not hold for SA teens in mental healthcare. Should parents emerge as potentially protective, leveraging parental involvement as a part of mental healthcare may offer new approaches to interrupt the effects of violence on young people's longterm health trajectories.

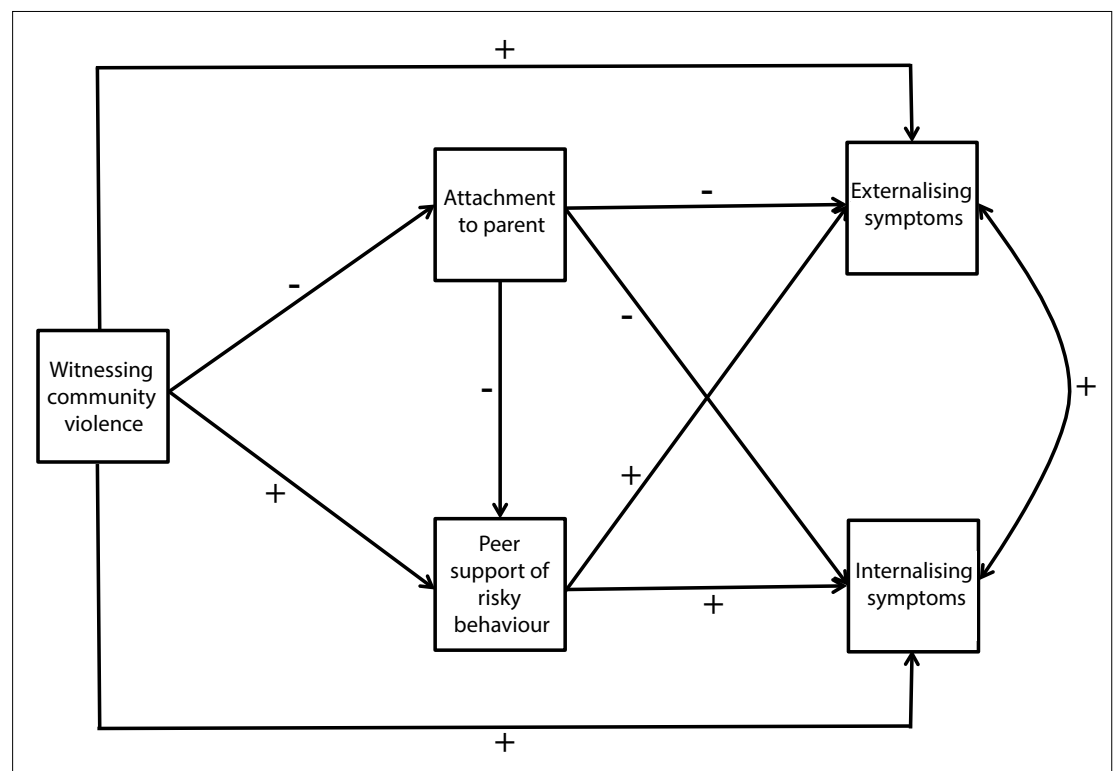

Fig. 1. Model of the theoretical relations between mental health, relationship and community violence variables. 
Findings related to the buffering role of families in the context of violence exposure are inconsistent. ${ }^{[65]}$ For example, more family organisation and support may reduce the negative impact of violence on children's mental health, ${ }^{[5,13,66]}$ but violence exposure may impede parental attachment ${ }^{[46]}$ and compromise the protective effects of social support in the context of high violence and the constant threat of harm. ${ }^{[67-69]}$ Hence, we expected community violence exposure to be cross-sectionally associated with weaker parental attachment and that low parental attachment would in turn be cross-sectionally related to increased externalising and internalising problems. However, we also hypothesised that stronger parental attachment would be associated with less engagement with risky peers and weaken the relations between violence exposure and both types of mental health symptoms (Fig. 1).

Importantly, the association between violence exposure and mental health may differ for male and female SA youth. Previous studies primarily conducted in the USA and with community- and schoolbased populations indicate that life stressors predict more depression among adolescent girls than boys, ${ }^{[70]}$ suggesting that adolescence is a particularly vulnerable period for girls to experience stress. ${ }^{[7]}$ Other research suggests that males may be more vulnerable to violence exposure. ${ }^{[72]}$ The emergence of gender differences in internalising problems occurs during adolescence, with girls suffering more than boys. ${ }^{[6,73]}$ Boys and girls may react differently to violence exposure, ${ }^{[37]}$ and gender may moderate the pathways between violence exposure and mental health difficulties and the role of parents and peers as buffers. ${ }^{[7]}$ We therefore hypothesised that boys would endorse more externalising than internalising problems and that girls would report more internalising than externalising symptoms, but we expected similar reports of exposure to violence for males and females. We did not make other gender-related predictions owing to the lack of consistency in prior research on which to base hypotheses.

\section{Objectives}

Guided by the path model in Fig. 1, we tested the differential associations between exposure to community violence and internalising and externalising problems in SA adolescents receiving mental healthcare against the backdrop of historical discrimination and lack of opportunities. We extended prior research in important ways. First, we focused on adolescents receiving mental health services rather than the school-based, community or convenience samples typical of most of the research both globally and in SA. These youth had problems severe enough to warrant services, and findings therefore reveal patterns for teens with substantial mental ill health. Second, we went beyond direct associations between violence exposure and mental health to elucidate possible pathways in which adolescents' relationships with parents and peers may lessen the strength of the relations between violence exposure and SA adolescents' mental health. Third, few studies in SA have employed state-of-the-art analytical methods to unpack the cross-sectional associations between parent, peer and community violence and adolescent mental health problems. This study evaluated the unique contributions of these factors by going beyond simple correlations and accounting for the relationships between all variables simultaneously within a single model. Fourth, findings can shed new light on the differential pathways to two types of mental health problems for SA youth in care, internalising and externalising. Finally, by building on the SPF, we examined a theoretically relevant path model and the role of two well-established psychosocial factors, parents and peers, that might mitigate or exacerbate the links between violence exposure and mental health problems.

\section{Methods \\ Procedures}

Study procedures were approved by all collaborating institutional review boards. This study reports on baseline data from a pilot study testing a family-based HIV prevention programme adapted for SA. Primary caregivers (hereafter referred to as 'parents') and their adolescent children were recruited from four urban inpatient and outpatient mental health clinics in the public health system (i.e. serving the majority who cannot afford private care) in the Western Cape: two tertiary general hospitals, one psychiatric hospital, and a dedicated mental health programme in the community. Most families were recruited from outpatient (97\%) v. inpatient (3\%) services. Clinic staff identified eligible families, informed them of the study, and requested permission to forward their contact information to research staff. One hundred and thirty-one families agreed to their information being forwarded and were subsequently contacted by the research co-ordinator, who explained the project in detail. Of the 131 families referred to the research study by the clinics, $11(8 \%)$ declined to participate. The remaining families were screened for eligibility and scheduled for the baseline assessment and workshop.

At the beginning of the baseline assessment, parents and teens separately reviewed consent and assent documents and then completed $1 \frac{1}{2}$-hour assessments using a combination of audio computer-assisted technology and interviews. Assessors spoke the participants' language and remained in the room to answer questions. Most of the instruments had been used in SA in previous research, and all instruments were translated and back-translated into Afrikaans and isiXhosa, two SA languages widely spoken in the Western Cape. Participants selected the language of their assessments, including English. Participants received transport money (ZAR30 = USD3) and a shopping voucher or cash (ZAR50 = USD5) for their time. Adolescents reported on their mental health, exposure to community violence, parental attachment and peer risk behaviour. Parents reported on adolescents' internalising and externalising problems.

\section{Participants}

Participants were 120 caregivers (94\% female) and their 12 - 18-yearold (mean (standard deviation (SD) 14.39 (1.82) years) children (53\% male, $67 \%$ black African and $33 \%$ mixed race). Teens were excluded from the study if they were outside the age range, were unable to understand and provide assent, did not speak English, Afrikaans or isiXhosa, or did not have parental consent. Most youth participated with their biological mother (76\%) or grandmother (8\%). Parents reported an average monthly income of ZAR3 973 (USD397), indicating a relatively low-income sample. At least $90 \%$ of parents reported having electricity, a television, a cellphone and a refrigerator.

\section{Measures}

Demographics. Parents reported on their education, income and relationship to the adolescent participant.

Witnessing community violence. An adapted version of the Witnessing Community Violence scale from the Social and Health Assessment (SAHA) ${ }^{[75]}$ was used. Evidence for SAHA's psychometric properties has been documented extensively. ${ }^{[6,77]}$ Adaptations for this study used an 'ever' time frame instead of the 'past year', removed two types of violence ('seeing a seriously wounded person after an incident of violence' and 'seeing someone threatened or harmed because of their race or ethnicity'), and altered the number of times an event was witnessed from 'none, $1-2,3-5,6-9,10+$ times' to 'never, 1, 2, 3+ times'. Adolescents reported whether they 
ever witnessed five types of community violence: seeing someone: (i) beaten up or mugged; (ii) threatened with serious physical harm; (iii) shot or shot at with a gun; (iv) attacked or stabbed with a knife; and $(v)$ chased by gangs or individuals. In cases of witnessed events, youth reported how many times this occurred (where $0=$ never, $1=$ once, $2=$ twice, and $3=$ three or more times). Higher scores indicated more times violence was witnessed. Internal consistency was acceptable $(\alpha=0.72)$ for the adapted scale.

Mental health. Adolescent mental health was evaluated using parent and youth reports on the Child Behavior Checklist (CBCL) and Youth Self-Report (YSR), respectively. ${ }^{[78]}$ The reliability and validity of the YSR and CBCL are well established, including for use in clinical and community samples and across diverse cultural settings. ${ }^{[79]}$ Versions of both measures translated into Afrikaans were used, ${ }^{[80]}$ and an isiXhosa version was used for the CBCL. The YSR had not previously been translated into isiXhosa. Parents and youth reported on the occurrence of a problem using a scale from 0 to 2 over the past 6 months, where $0=$ not true, $1=$ somewhat or sometimes true, and 2 = very true or often true. Sample items from the YSR include 'I cry a lot', 'I get in many fights', and 'I act without stopping to think'. Sample items from the CBCL include 'My child': 'cries a lot', 'gets in many fights', and 'is impulsive or acts without thinking. The YSR and CBCL each generate raw and $t$-scores for internalising (e.g. sadness, anxiety) and externalising (e.g. fighting, aggression) problems. Higher scores indicate more problems. Internal reliability was high for internalising ( $\alpha=0.86$ for YSR; $\alpha=0.90$ for CBCL) and externalising ( $\alpha=0.90$ for YSR; $\alpha=0.92$ for CBCL) symptoms.

Parent-teen relationship. Teens completed the Inventory of Parent Attachment ${ }^{[81]}$ to indicate their perceptions of parental warmth and support. Sample items are 'My parent accepts me as I am' and 'I tell my parent about my problems and troubles'. Items are scored from 1 to 5 , where $1=$ 'almost never or never true', and $5=$ 'almost always or always true.' Higher scores represent more secure attachment, mutual trust, open communication and less alienation. The measure has substantial reliability and validity for mid-late adolescents. ${ }^{[81]}$ Internal consistency was $\alpha=0.81$.

Peer influence. Five items from Jessor and Jessor's Health Questionnaire ${ }^{[82]}$ evaluated peer support of risky behaviour. Three items asked how many of the respondent's friends 'drink alcohol/ use marijuana/smoke cigarettes', rated on a 4 -point scale $(1=$ none, $2=$ some of them, $3=$ most of them, $4=$ all of them), and two items asked about peer approval of substance use (e.g. 'how do most of your friends feel about someone your age drinking alcohol/using marijuana?'), rated on a 4-point scale ( $1=$ strongly disapprove, $2=$ disapprove, 3 = they don't seem to care, $4=$ approve). Youth also reported on friends' sexual behaviour: 'Think of all your friends. How many of them have had sexual intercourse with someone of the opposite sex?', also rated on a 4 -point scale $(1=$ almost none to $4=$ all of them). Internal consistency was $\alpha=0.74$.

\section{Data analysis}

Data analysis proceeded in two steps consistent with the study objectives. First, the direct effects of theoretical predictors on mental health symptoms in boys and girls were examined via simple linear regressions in SPSS version 23 (IBM Corp., USA). Direct effects have potential clinical relevance. For example, if a significant association is demonstrated between low parent attachment and externalising symptoms in boys, observation of poor attachment in male patients could cue providers to assess for externalising behaviours. However, direct effects are silent with regard to the relations among multiple, potentially related variables, and are subject to inflated type 1 experiment-wise error.

To address these limitations, path analyses were conducted in Mplus, 6th edition (Muthén \& Muthén, USA). ${ }^{[83]}$ The theoretical model was tested using a two-group (by gender) path model. Externalising and internalising symptoms were regressed onto theoretical proximal (parent and peer relationship) and distal (community violence) predictors. This approach enabled estimation of any indirect effects of distal via proximal predictors on mental health outcomes (e.g. the indirect effect of witnessing community violence on externalising symptoms through parent attachment). Model goodness of fit was evaluated using three fit indices: root mean square error of approximation (RMSEA), ${ }^{[84]}$ standardised root mean square residual (SRMR) and comparative fit index (CFI). ${ }^{[85]}$ Respective cutoffs of $\leq 0.06$ and 0.08 for RMSEA and SRMR, and $\geq 0.95$ for CFI, were used to conclude good fit between the observed data and the hypothesised model. ${ }^{[86]}$

\section{Results}

Descriptive statistics for boys and girls are presented in Table 1. Boys reported significantly higher rates of witnessing community violence than girls, although the difference was small; otherwise there were no significant gender differences. Parent- and youth-reported symptom ratings ${ }^{[78]}$ revealed high rates of mental health problems. Using a cutoff score cited in a study of HIV-positive youth in Cape Town, ${ }^{[87]}$ and consistent with methods in previous research ${ }^{[42]} 72 \%$ and $71 \%$ scored in the clinical range for externalising and internalising problems based on parent or child report.

\section{Direct relations between model components}

The direct cross-sectional relations between theoretical predictor variables and mental health outcomes are summarised in Table 2. Among boys, witnessing community violence, low parent attachment, and peer support of risky behaviour each directly predicted externalising but not internalising symptoms. Among girls, no significant direct associations emerged.

\section{Path analyses}

To test the theoretical model in Fig. 1, externalising and internalising symptoms were regressed on parent attachment, peer support of risky behaviour, and witnessing community violence using a two-group (by gender) path model. Both proximal predictors (parent and peer relationships) were regressed on the distal predictor (community violence), and peer support of risky behaviour was regressed on parent attachment. Residual errors of externalising and internalising symptoms measures were correlated. To account for the significant gender difference in witnessing community violence, the intercept of this variable was allowed to vary across groups. The model was justidentified, RMSEA $=0.000$ with $90 \%$ confidence interval $0.00-0.00$, $\mathrm{SRMR}=0.00$, CFI $=1.00$.

Standardised and unstandardised path coefficients for boys and girls are presented in Table 3. Each standardised path coefficient indicates the estimated $1 \mathrm{SD}$ change in the outcome variable given a $1 \mathrm{SD}$ increase in the predictor variable, providing an easily interpretable estimate of effect size. Among boys, paths from both community violence and low parent attachment to externalising symptoms were statistically significant. Additionally, the path from community violence to peer support of risky behaviour was highly significant for boys. Comparison of the present (unconstrained) model to a similar one in which the path from community violence to peer relationships was constrained to be equal between genders 
Table 1. Descriptive statistics in boys and girls at baseline

\begin{tabular}{|c|c|c|c|c|}
\hline Variable $^{\dagger}$ & $\begin{array}{l}\text { Total sample } \\
(N=120)\end{array}$ & Boys $(N=64)$ & Girls $(N=56)$ & $\begin{array}{l}\text { Between-group } \\
\text { difference }\end{array}$ \\
\hline Age (years), mean (SD) & $14.39(1.82)$ & $14.19(1.88)$ & $14.63(1.73)$ & $t(118)=-1.32$ \\
\hline Black race, $n(\%)$ & $80(67)$ & 43 (67) & $37(66)$ & $\chi^{2}(1,120)=0.02$ \\
\hline Mixed race, $n(\%)$ & $40(33)$ & $21(33)$ & $19(34)$ & $\chi^{2}(1,120)=0.02$ \\
\hline Parent education, $n(\%)$ & & & & $\chi^{2}(5,116)=6.89$ \\
\hline No schooling & $4(3)$ & $2(3)$ & $2(4)$ & \\
\hline Std $1 /$ Gr 3 through Std 9/Gr 11 & $73(63)$ & $34(56)$ & $39(71)$ & \\
\hline Std 10/Gr 12 (matric) & $25(21)$ & $17(28)$ & $8(14)$ & \\
\hline Post-matric/diploma/courses & $10(9)$ & $7(11)$ & $3(5)$ & \\
\hline Graduate/degree & $2(2)$ & $1(2)$ & $1(2)$ & \\
\hline Postgraduate & $2(2)$ & 0 & $2(4)$ & \\
\hline Household income (ZAR/month), mean (SD) & $3973.10(5038.01)$ & $3799.07(5463.42)$ & $4182.73(4526.27)$ & $t(95)=-0.37$ \\
\hline Externalising $t$-score ${ }^{\ddagger}$ mean (SD) & $66.59(10.46)$ & $66.09(10.54)$ & $67.16(10.43)$ & $t(118)=-0.56$ \\
\hline Internalising $t$-score ${ }^{*}$ mean (SD) & $67.33(9.34)$ & $66.17(9.68)$ & $68.66(8.85)$ & $t(118)=-1.46$ \\
\hline Attachment to parent, ${ }^{\varsigma}$ mean (SD) & $83.78(15.33)$ & $84.32(15.81)$ & $83.18(14.89)$ & $t(117)=0.40$ \\
\hline Peer support of risky behaviour, ${ }^{\S}$ mean (SD) & $12.11(4.26)$ & $12.57(4.45)$ & $11.59(4.02)$ & $t(117)=1.26$ \\
\hline Witnessing community violence, ${ }^{\varsigma}$ mean (SD & $7.03(3.90)$ & $8.02(3.95)^{*}$ & $5.93(3.57)^{*}$ & $t(117)=3.01$ \\
\hline
\end{tabular}

Table 2. Direct relations between mental health, relationships and community violence

\begin{tabular}{|c|c|c|c|c|c|c|c|c|c|c|}
\hline \multirow[b]{2}{*}{ Variable } & \multicolumn{5}{|c|}{ Externalising symptoms } & \multicolumn{5}{|c|}{ Internalising symptoms } \\
\hline & $F$ & df & $R^{2}$ & $\beta$ & $p$-value & $F$ & df & $R^{2}$ & $\beta$ & $p$-value \\
\hline \multicolumn{11}{|l|}{ Boys } \\
\hline Attachment to parents & 10.31 & 1,61 & 0.13 & -0.38 & 0.002 & 1.96 & 1,61 & 0.03 & - & 0.170 \\
\hline Peer support of risky behaviour & 6.51 & 1,61 & 0.10 & 0.31 & 0.013 & 0.85 & 1,61 & 0.01 & - & 0.360 \\
\hline Witnessing community violence & 10.62 & 1,61 & 0.39 & 0.24 & 0.002 & 0.19 & 1,61 & 0.00 & - & 0.668 \\
\hline \multicolumn{11}{|l|}{ Girls } \\
\hline Attachment to parents & 0.15 & 1,54 & 0.00 & - & 0.704 & 0.04 & 1,54 & 0.00 & - & 0.852 \\
\hline Peer support of risky behaviour & 0.19 & 1,54 & 0.00 & - & 0.663 & 0.00 & 1,54 & 0.00 & - & 0.983 \\
\hline Witnessing community violence & 0.53 & 1,54 & 0.01 & - & 0.470 & 0.18 & 1,54 & 0.00 & - & 0.677 \\
\hline
\end{tabular}

showed a significant difference in model fit, $\chi^{2}(1)=5.37, p=0.020$, indicating that the path was significantly stronger for boys than girls. Among girls, a significant effect emerged from low parent attachment to peer support of risky behaviour. There was no evidence of additional significant differences between genders in direct parameter estimates, or of significant indirect effects in either gender (all $p$-values $>0.05$ ).

Finally, we sought to test convergent and discriminant validity between significant predictor variables and externalising v. internalising outcomes in boys. For each significant path, this was accomplished by comparing the unconstrained model with a similar one in which the paths from the relevant predictor variable (e.g. community violence) to both externalising and internalising symptoms were set equal to each other among boys. In support of the stronger effects of witnessing community violence on externalising v. internalising symptoms, the unconstrained model provided a significantly better fit, $\chi^{2}(1)=5.54, p=0.020$. For the paths from parent attachment to mental health outcomes, the difference in fit between the constrained and unconstrained models approached but did not reach significance, $\chi^{2}(1)=3.66, p=0.056$.

\section{Discussion}

The consequences of community violence exposure for SA adolescents' mental health are gravely concerning. Identifying the factors that drive or mitigate psychological problems in the context of persistent community violence is essential to SA's future. This study examined a single path model guided by previous theory and research, but we recognise that the associations are complex and multifaceted. Unsurprisingly, in this study of youth in mental healthcare, the majority had clinically significant externalising and internalising problems according to parent or adolescent report, and youth reported high rates of witnessing community violence. Boys described significantly more community violence exposure than did girls, although the difference was small; both genders were exposed to high rates of community violence. These findings support previous evidence of polyvictimisation and high rates of violence exposure among SA youth. ${ }^{[14]}$ In addition, mental health symptoms were strongly associated with parent, peer and community violence exposure, advancing the science on the selection and delivery of evidence-based interventions. Unexpectedly, results revealed stronger patterns for boys than girls, underscoring the need for 


\begin{tabular}{|c|c|c|c|c|c|}
\hline Pathway & Standardised $\beta$ & SE & Unstandardised $\beta$ & $90 \% \mathrm{CI}$ & $p$-value ${ }^{\dagger}$ \\
\hline \multicolumn{6}{|l|}{ Boys } \\
\hline \multicolumn{6}{|l|}{ Externalising symptoms on: } \\
\hline Attachment to parent & -0.33 & 0.10 & -0.28 & $-0.43--0.13$ & 0.002 \\
\hline Peer support of risky behaviour & 0.16 & 0.12 & 0.47 & $-0.14-1.08$ & 0.204 \\
\hline Witnessing community violence & 0.26 & 0.12 & 0.89 & $0.20-1.58$ & 0.033 \\
\hline \multicolumn{6}{|l|}{ Internalising symptoms on: } \\
\hline Attachment to parent & -0.17 & 0.12 & -0.11 & $-0.24-0.02$ & 0.175 \\
\hline Peer support of risky behaviour & 0.12 & 0.14 & 0.27 & $-0.27-0.81$ & 0.411 \\
\hline Witnessing community violence & -0.03 & 0.14 & -0.07 & $-0.67-0.54$ & 0.858 \\
\hline \multicolumn{6}{|l|}{ Attachment to parent on: } \\
\hline Peer support of risky behaviour & -0.01 & 0.11 & 0.00 & $-0.06-0.05$ & 0.917 \\
\hline Witnessing community violence & -0.14 & 0.12 & -0.57 & $-1.39-0.26$ & 0.257 \\
\hline \multicolumn{6}{|l|}{ Peer support of risky behaviour on: } \\
\hline Witnessing community violence & 0.49 & 0.10 & 0.55 & $0.34-0.75$ & $0.000^{*}$ \\
\hline \multicolumn{6}{|l|}{ Girls } \\
\hline \multicolumn{6}{|l|}{ Externalising symptoms on: } \\
\hline Attachment to parent & -0.02 & 0.14 & -0.02 & $-0.25-0.21$ & 0.884 \\
\hline Peer support of risky behaviour & 0.04 & 0.14 & 0.14 & $-0.71-0.99$ & 0.786 \\
\hline Witnessing community violence & 0.09 & 0.14 & 0.36 & $-0.55-1.27$ & 0.516 \\
\hline \multicolumn{6}{|l|}{ Internalising symptoms on: } \\
\hline Attachment to parent & 0.02 & 0.14 & 0.01 & $-0.17-0.19$ & 0.896 \\
\hline Peer support of risky behaviour & 0.01 & 0.14 & 0.03 & $-0.63-0.70$ & 0.932 \\
\hline Witnessing community violence & -0.06 & 0.14 & -0.17 & $-0.89-0.54$ & 0.688 \\
\hline \multicolumn{6}{|l|}{ Attachment to parent on: } \\
\hline Peer support of risky behaviour & -0.33 & 0.12 & -0.09 & $-0.15--0.03$ & 0.009 \\
\hline Witnessing community violence & -0.20 & 0.13 & -0.83 & $-1.73-0.07$ & 0.130 \\
\hline \multicolumn{6}{|l|}{ Peer support of risky behaviour on: } \\
\hline Witnessing community violence & 0.09 & 0.13 & 0.10 & $-0.14-0.34$ & $0.489^{*}$ \\
\hline
\end{tabular}

gender-specific programming. This cross-sectional study sheds new light on the possible pathways from witnessing community violence to mental health problems among SA adolescents.

Consistent with previous research and part of our hypothesis, externalising but not internalising symptoms were related to witnessing community violence among boys; among girls, witnessing community violence was not directly associated with either internalising or externalising symptoms. These results extend previous research beyond Western and SA school- and communitybased samples and highlight the potential consequences of witnessing community violence, specifically on male adolescent mental health. Theory suggests at least four ways in which community violence exposure may be associated with externalising more than internalising problems, underscoring the complexity of these associations. For example, according to social learning theory, individuals who witness violence may adopt violent behaviours by identifying with the aggressor through modelling. ${ }^{[88]}$ Alternatively, individuals may adopt violent behaviours to avoid feelings of helplessness and fear. A third possibility is that individuals exposed to violence may internalise aggression as a legitimate approach to resolving conflicts. ${ }^{[89]}$ This theory may be particularly relevant to adolescents who are developing coping skills to deal with stress. Finally, the pathological adaptation model argues that individuals become desensitised to chronic violence, becoming emotionally numb or blunted. ${ }^{[90]}$ Such desensitisation is adaptive in the short term, but increases adolescent risk for subsequent violence if it becomes a habitual response. Future research is needed to understand the differential mechanisms proposed by alternative theories with special attention to gender differences.

This cross-sectional path analysis examined two social factors, parental attachment and peer support for risk behaviour, previously related to adolescent mental health and hypothesised to predict mental health outcomes in the $\mathrm{SPF}^{[38]}$ but untested in the context of witnessing community violence in SA. Consistent with expectations, community violence exposure and low parental attachment were each related to externalising problems, but contrary to the hypothesis, these linkages were unique to boys, suggesting that boys' mental health problems may be more affected by community violence exposure and specific social drivers (e.g. parental attachment) than those of girls in the SA context. These findings contrast with previous research indicating that social support fails to buffer the impact of violence exposure on adolescent mental health in high-violence contexts. ${ }^{[25,69]}$

Similarly, community violence exposure was related to peer support of risky behaviour, but again only for boys, and significantly more strongly than for girls. It is possible that witnessing community violence exerts a stronger influence on boys' peer relationships than those of girls; boys who see violence may choose peers who approve of high-risk behaviour. Alternatively, for SA boys, witnessing community violence and externalising symptoms may be part of a 
larger problem behaviour syndrome ${ }^{[82]}$ that includes associating with peers who engage in risk behaviour. Understanding how girls are protected from these patterns is an important direction for future research and may reveal strategies that could be used effectively with boys. Indeed, only one effect emerged for girls in this study: girls' reports of low parent attachment were significantly associated with more peer support of risky behaviour. This finding supports previous research in the USA indicating that strong mother-daughter attachment may protect girls from associating with risky peers, ${ }^{[44]}$ but offers new evidence in the context of SA girls receiving mental health services.

Findings illuminate potential strategies to minimise the negative effects of community violence on adolescent mental health. That parental attachment and community violence exposure each emerged as an important factor independently related to externalising problems points to the promising role of parents, even in a highviolence context. For example, strengthening parent-teen attachment may improve adolescents' mental health outcomes despite persistent violence exposure. Likewise, the association of community violence with peer support of risk behaviour suggests that shifting adolescent peer networks away from teens who support high-risk behaviour may lessen exposure to community violence. Future studies are needed to evaluate these hypotheses.

The study findings underscore the complexity of the pathways examined here and highlight the need for future research to further unpack these results. As an example, polyvictimisation is common among SA youth, ${ }^{[1]}$ and it is therefore possible that the patterns found in this study apply to other forms of violence. Indeed, exposure to community violence may simply be a proxy for other violence experiences, such as sexual abuse or physical assault. ${ }^{[22,93]}$ Future research is critical to tease apart the unique pathways to mental health problems across different types of violence exposure and to other possible underlying mechanisms beyond parental attachment and peer influence. Research with larger samples and longitudinal data will strengthen the ability to detect temporal relationships and differentiate such linkages. Likewise, distinguishing the more common male v. female violence exposure experiences may point to differential intervention targets for gender-specific programming.

\section{Study limitations}

Findings should be considered in the light of study limitations. Data were self-reported and may reflect social desirability biases. However, parents reported on teens' mental health problems, offering some method variance. The study tested cross-sectional relationships, and causal interpretations are therefore not possible, including the specific pathways proposed in Fig. 1. Yet, by using path analysis to control for the associations among variables, the proposed framework can provide direction for future study of longitudinal associations and direction of effects. For example, it is possible that externalising problems predict community violence exposure rather than vice versa. The small sample limited power to detect nuanced pathways and the ability to test alternative path models to identify best fit. Future research with larger samples would allow testing of different models, unique pathways, and additional mediators that may explain the association between violence exposure and mental health. Patterns may not generalise beyond SA adolescents, although findings are inclusive of the three main ethnic groups in the Western Cape. This study tested a single path model, although the relationships between the variables are likely to be more complex. However, this article provides a first step to elucidate the pathways from community violence exposure to mental health problems among a unique sample of SA adolescents in mental healthcare.

\section{Conclusions}

This study advances the science on the associations between witnessing community violence, parental attachment, and peer support for risk behaviour with externalising and internalising problems among SA adolescents receiving mental healthcare. Using path analysis, a robust approach that accounts for associations between all variables, this study identified differential effects for boys and girls, underscoring the need for gender-specific programming to address the impact of community violence on adolescent mental health for youth receiving mental health services.

\section{Declaration. None.}

Acknowledgements. This research was supported by National Institute of Mental Health grant R34MH092251 to the University of Illinois at Chicago and the Human Sciences Research Council (principal investigators: GD and PN). We thank the parents and adolescents who participated in the study, and gratefully acknowledge the administrators and clinical staff at the four mental health clinics in the Western Cape who worked with us to enrol families.

Author contributions. GD and PN were the principal investigators of the study and oversaw all aspects of study implementation, including subject recruitment and retention, data collection, intervention delivery, and data entry and analysis. GD wrote the manuscript with input from the co-authors. AK, supervised by MEM-A, conducted the data analyses and wrote the initial draft of the results. EE, co-investigator, assisted in writing the proposal for grant funding and conducted/supervised all data preparation for analysis, including entry, cleaning and database creation. CLW, AK and LS were co-investigators who also assisted in writing and editing the manuscript. RV was the study's project co-ordinator, oversaw the day-to-day operations of the project, namely staff hiring and training, subject recruitment, institutional review board protocol submissions, and data collection and entry, and acted as the liaison for all collaborating partners. AN was the project director who supervised RV, and JM was the recruitment and retention co-ordinator for participants. Each reviewed the manuscript prior to submission.

Funding. National Institute of Mental Health (R34MH092251).

Conflicts of interest. None.

1. Hervish A, Clifton D. Status report on adolescents and young people in sub-Saharan Africa: Opportunities and challenges. United Nations Population Fund, 2012. https://assets.prb.org/pdf12/ status-report-youth-subsaharan-Africa.pdf (accessed 21 January 2019).

2. HIV and AIDS in South Africa. AVERT, 2018. https://www.avert.org/infographics/hiv-and-aidssouth-africa (accessed 18 January 2019).

3. Kaminer D, Hardy A, Heath K, et al. Gender patterns in the contribution of different types of

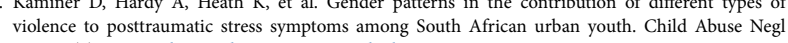
violence to posttraumatic stress symptoms among South Afric
2013;37(5):320-330. https://doi.org/10.1016/j.chiabu.2012.12.011

2013;37(5):320-330. https://doi.org/ 10.1016/j.chiabu.2012.12.011
4. Stein DJ, Seedat S, Herman A, et al. Lifetime prevalence of psychiatric disorders in South Africa. Br J Psychiatry 2008;192(2):112-117. https://doi.org/10.1192/bjp.bp. 106.029280

5. Foster H, Brooks-Gunn J. Children's exposure to community and war violence and mental health in four African countries. Soc Sci Med 2015;146:292-299. https://doi.org/10.1016/j.socscimed.2015.10.020

6. Ward CL, Artz L, Leoschut L, et al. Sexual violence against children in South Africa: A nationally representative cross-sectional study of prevalence and correlates. Lancet Glob Health 2018;6(4):e460-e468. https://doi.org/10.1016/S2214-109X(18)30060-3

7. Ward CL, Flisher AJ, Zissis C, et al. Exposure to violence and its relationship to psychopathology in adolescents. Inj Prev 2001;7(4):297-301. https://doi.org/10.1136/ip.7.4.297

8. South African Police Service Strategic Management. Annual Report 2016/2017. SAPS, 2017. https:// nationalgovernment.co.za/department_annual/201/2017-south-african-police-service-(saps)-annualreport.pdf (accessed 21 January 2019).

9. Collings SJ, Valjee SR, Penning SL. Development and preliminary validation of a screen for interpersonal childhood trauma experiences among school-going youth in Durban, South Africa. interpersonal childhood trauma experiences among school-going youth in Durban, South $\mathrm{A}$.
J Child Adolesc Ment Health 2013;25(1):23-34. https://doi.org/10.2989/17280583.2012.722552

10. Goga K. The drug trade and governance in Cape Town. Institute for Security Studies, 2014. https:// issafrica.org/research/papers/the-drug-trade-and-governance-in-cape-town (accessed 21 January 2019). 
11. Groenewald P, Bradshaw D, Daniels J, et al. Cause of Death and Premature Mortality in Cape Town, 2001 - 2006. Cape Town: South African Medical Research Council, 2008. https://www.westerncape gov.za/Text/2008/11/cause_of_death_and_premature_mortality_in_cape_town_5_november_2008.pdf (accessed 21 January 2019).

12. Ward CL, Martin E, Theron C, et al. Factors affecting resilience in children exposed to violence. S Afr J Psychol 2007;37(1):165-187. https://doi.org/10.1177/008124630703700112

13. Shields N, Nadasen K, Pierce L. The effects of community violence on children in Cape Town, South Africa. Child Abuse Negl 2008;32(5):589-601. https://doi.org/10.1016/j.chiabu.2007.07.010

4. Kaminer D, du Plessis B, Hardy A, et al. Exposure to violence across multiple sites among young South African adolescents. Peace Confl 2013;19(2):112-124. https://doi.org/10.1037/a0032487

15. Norman R, Schneider M, Bradshaw D, et al. Interpersonal violence: An important risk factor for disease and injury in South Africa. Popul Health Metr 2010;8(32):1-12. https://doi.org/10.1186/1478-7954-8-32

16. World Health Organization. Adolescent Mental Health. Geneva: WHO, 2018. https://www.who.int news-room/fact-sheets/detail/adolescent-mental-health (accessed 25 March 2019)

17. Das-Munshi J, Lund C, Mathews C, et al. Mental health inequalities in adolescents growing up in postapartheid South Africa: Cross-sectional survey, SHaW Study. PLoS One 2016;11(5):e0154478. https://doi. org/10.1371/journal.pone.0154478

18. Gevers A, Flisher AJ. Mental health risk behavior. In: Kibel M, Lake L, Pendlebury S, Smith C, eds. South African Child Gauge 2009/2010. Cape Town: Children's Institute, University of Cape Town, 2010.

19. Patel V, Flisher A, Hetrick S, et al. Mental health of young people: A global public health challenge. Lancet 2007:369(9569):1302-1313. https/1doi $0 \mathrm{rg} 10.1016 / 50140-6736(07) 60368-7$

20. Du Plessis B, Kaminer D, Hardy A, et al. The contribution of different forms of violence exposure to internalizing and externalizing symptoms among young South African adolescents. Child Abuse Negl 2015;45:80-89. https://doi.org/10.1016/j.chiabu.2015.02.02

1. Miller LS, Wasserman GA, Neugebauer R, et al. Witnessed community violence and antisocial behavior in high-risk, urban boys. J Clin Child Psychol 1999;28(1):2-11. https://doi.org/10.1207/ s15374424jсcp2801_1

22. Youngstrom E, Weist MD, Albus KE. Exploring violence exposure, stress, protective factors, and behavioral problems among inner-city youth. Am J Community Psychol 2003;32(1-2):115-129. https:// doi.org/10.1023/A:102560722612

23. Jennings A. The Damaging Consequences of Violence and Trauma: Facts, Discussion Points, and Recommendations for the Behavioral Health System. Alexandria, Va: National Technical Assistance Center for State Mental Health Planning, 2004.

24. Copeland-Linder N, Lambert SF, Ialongo N. Community violence, protective factors, and adolescen mental health: A profile analysis. J Clin Child Adolesc Psychol 2010;39(2):176-186. https://doi org $/ 10.1080 / 15374410903532601$

25. Stansfeld SA, Rothon C, Das-Munshi J, et al. Exposure to violence and mental health of adolescents: South African Health and Well-being Study. BJPsych Open 2017;3(5):257-264. https://doi.org/10.1192/ bjpo.bp.117.00486

6. Sui X, Masser K, Kessels, L. et al. Violence exposure in South African adolescents: Differential and cumulative effects on psychological functioning. J Interpers Violence 2018;1-27. https://doi. org/10.1177/0886260518788363

27. Dubé C, Gagné M-H, Clement M-E, Chamberland C. Community violence and associated psychological problems among adolescents in the general population. J Child Adolesc Trauma 2018;11(4):411-420. https://doi.org/10.1007/s40653-018-0218-8

28. Zinzow H, Ruggiero K, Resnick H, et al. Prevalence and mental health correlates of witnessed parental and community violence in a national sample of adolescents. J Child Psychol Psychiatry 2009;50(4):441450. https://doi.org/10.1111/j.1469-7610.2008.02004.x

29. Cluver L, Gardner F, Operario D. Psychological distress amongst AIDS-orphaned children in urban South Cluver L, Gardner F, Operario D. Psychological distress amongst AIDS-orphaned children in urban South Africa. J Child Psychol Psychiatry 2007;48(8):755-763. https://doi.org/10.1111/j.1469-7610.2007.01757.x 0. Costello J, Erkanli A, Angold A. Is there an epidemic of child or adolescent depressio
Psychiatry 2006;47(12):1263-1271. https://doi.org/10.1111/j.1469-7610.2006.01682.x

31. Steinberg L. Cognitive and affective development in adolescence. Trends Cogn Sci 2005;9(2):69-74 https://doi.org/10.1016/j.tics.2004.12.005

32. Margolin G, Gordis EB. The effects of family and community violence on children. Annu Rev Psychol 2000;51:445-479. https://doi.org/10.1146/annurev.psych.51.1.44

33. Noll JG, Trickett PK, Putnam FW. A prospective investigation of the impact of childhood sexual abuse on the development of sexuality. J Consult Clin Psychol 2003;71(3):575-586. https://doi.org/10.1037/0022 006x.71.3.575

34. Institute of Medicine. Violence Prevention in Low- and Middle-income Countries: Finding a Place on the Global Agenda. Washington, DC: National Academies Press, 2008.

35. Widom CS, Czaja SJ, Dutton MA. Childhood victimization and lifetime revictimization. Child Abuse Negl 2008;32(8):785-796. https://doi.org/10.1016/j.chiabu.2007.12.006

36. Williams SL, Williams DR, Stein DJ, et al. Multiple traumatic events and psychological distress: The South African Stress and Health Study. J Trauma Stress 2007;20(5):845-855. https://doi.org/10.1002/its.20252 Kaminer D, Eagle G. Traumatic Stress in South Africa. Johannesburg: Wits University Press, 2010.

37. Kaminer D, Eagle G. Traumatic Stress in South Africa. Johannesburg: Wits University Press, 2010.
38. Donenberg GR, Pao M. Youths and HIV/AIDS: Psychiatry's role in a changing epidemic. I Am Acad Donenberg GR, Pao M. Youths and HIV/AIDS: Psychiatry's role in a changing epidemic. J Am
Child Adolesc Psychiatry 2005;44(8):728-747. https://doi.org/10.1097/01.chi.0000166381.68392.02

39. Donenberg G, Emerson E, Mackesy-Amiti M, et al. Sexual risk among African American girls seeking psychiatric care: A social-personal framework. J Consult Clin Psychol 2018;86(1):24-38. https://doi. org/10.1037/ccp0000270

40. Donenberg GR, Emerson E, Bryant FB, et al. Understanding AIDS-risk behavior among adolescents in psychiatric care: Links to psychopathology and peer relationships. J Am Acad Child Adol Psychiatry 2001;40(6):642-653. https://doi.org/10.1097/00004583-200106000-00008

41. Donenberg GR, Brown LK, Hadley W, et al. Family-based HIV-prevention program for adolescents with psychiatric disorders. In: Pequegnat W, Bell C, eds. Families and HIV/AIDS: Culture and Contextual Issues in Prevention and Treatment. New York: Springer, 2012.

42. Brown LK, Hadley W, Donenberg GR, et al. Project STYLE: A multisite RCT for HIV prevention among youths in mental health treatment. Psychiatr Serv 2014;65(3):338-344. https://doi.org/10.1176/appi. ps.201300095

43. Brown $\mathrm{LK}$, Whiteley $\mathrm{L}$, Houck $\mathrm{CD}$, et al. The role of affect management for HIV risk reduction for youth in alternative schools. J Am Acad Child Adolesc Psychiatry 2017;56(6):524-531. https://doi.org/10.1016/j. jaac.2017.03.010

44. Emerson E, Donenberg GR, Wilson HW. Health-protective effects of attachment among African American girls in psychiatric care. J Fam Psychol 2012;26(1):124-132. https://doi.org/10.1037/a0026352

45. Berman SL, Silverman WK, Kurtines WM. The effects of community violence on children an adolescents: Intervention and social policy. In: Bottoms BL, Kovera MB, McAuliff BD, eds. Children Social Science, and the Law. Cambridge: Cambridge University Press, 2002:301-321

46. Osofsky J. The impact of violence on children: Domestic violence and children. Future Child 1999;9(3):33-49. https://doi.org/10.2307/1602780

47. Cooley-Quille M, Boyd RC, Frantz E, et al. Emotional and behavioral impact of exposure to community violence in inner-city adolescents. J Clin Child Psychol 2001;30(2):199-206. https://doi.org/10.1207/ S15374424JCCP3002_7

48. Fitzpatrick KM. Exposure to violence and presence of depression among low-income African American youth. J Consult Clin Psychol 1993;61(3):528-531. https://doi.org/10.1037//0022-006x.61.3.528
49. McDonald CC, Richmond TR. The relationship between community violence exposure and mental health symptoms in urban adolescents. J Psychiatr Ment Health Nurs 2008;15(10):833-849. https://doi. $\mathrm{org} / 10.1111 / j .1365-2850.2008 .01321 . x$

50. Mohammad ET, Shapiro ER, Wainwright LD, et al. Impacts of family and community violence exposure on child coping and mental health. J Abnorm Child Psychol 2015;43(2):203-215. https://doi.org/10.1007/ s10802-014-9889-2

51. Nanni V, Uher R, Danese A. Childhood maltreatment predicts unfavorable course of illness and treatment outcome in depression: A meta-analysis. Am J Psychiatry 2012;169(2):141-151. https://doi. org/10.1176/appi.ajp.2011.11020335

52. Fowler PJ, Tompsett CJ, Braciszewski JM, et al. Community violence: A meta-analysis on the effect of exposure and mental health outcomes of children and adolescents. Dev Psychopathol 2009;21(1):227259. https://doi.org/10.1017/S0954579409000145

53. McLaughlin KA, Greif Green J, Gruber MJ, et al. Childhood adversities and first onset of psychiatric disorders in a national sample of US adolescents. Arch Gen Psychiatry 2012;69(11):1151-1160. https:// doi.org/10.1001/archgenpsychiatry.2011.2277

54. Donenberg GR, Bryant FB, Emerson E, et al. Tracing the roots of early sexual debut among adolescents in psychiatric care. J Am Acad Child Adolesc Psychiatry 2003;42(5):594-608. https://doi.org/10.1097/01. CHI.0000046833.09750.91

55. Lambert SF, Ialongo NS, Boyd RC, et al. Risk factors for community violence exposure in adolescence. Am J Comm Psychol 2005;36(1-2):29-48. https://doi.org/10.1007/s10464-005-6231-8

56. Fortuin J, van Geel M, Vedder P. Peer influences on internalizing and externalizing problems among adolescents: A longitudinal social network analysis. J Youth Adolesc 2015;44(4):887-897. https://doi. org/10.1007/s10964-014-0168-x

57. Voisin D, Jenkins EJ, Takahashi L. Toward a conceptual model linking community violence exposure to HIV-related risk behaviors among adolescents: Directions for research. J Adolesc Health 2011;49(3):230236. https://doi.org/10.1016/.j.jadohealth.2011.01.002

58. Garthe RC, Sullivan T, Kliewer W. Longitudinal relations between adolescent and parental behaviors, parental knowledge, and internalizing behaviors among urban adolescents. J Youth Adolesc 2015;44(4):819-832. https://doi.org/10.1007/s10964-014-0112-0

59. Goldner JS, Quimby D, Richards MH, et al. Relations of parenting to adolescent externalizing and internalizing distress moderated by perception of neighborhood danger. J Clin Child Adolesc Psychol 2016;45(2):141-154. https://doi.org/10.1080/15374416.2014.958838

60. Smokowski PR, Bacallao ML, Cotter KL, et al. The effects of positive and negative parenting practices on adolescent mental health outcomes in a multicultural sample of rural youth. Child Psychiatry Hum Dev 2015;46(3):333-345. https://doi.org/10.1007/s10578-014-0474-2

61. Donenberg GR, Wilson H, Emerson E, et al. Holding the line with a watchful eye: The impact of perceived parental permissiveness and parental monitoring on risky sexual behavior among adolescents in psychiatric care. AIDS Educ Prev 2002;14(2):138-157. https://doi.org/10.1521/aeap. 14.2.138.23899

62. Fearon PR, Bakermans-Kranenburg MJ, van Ijzendoorn MH, et al. The significance of insecure attachment and disorganization in the development of children's externalizing behavior: A meta-analytic study. Child Dev 2010;81(2):435-456. https://doi.org/10.1111/j.1467-8624.2009.01405.x

63. Hoeve M, Stams GJJM, van der Put CE, et al. A meta-analysis of attachment to parents and delinquency. J Abnorm Child Psychol 2012;40(5):771-785. https://doi.org/10.1007/s10802-011-9608-1

64. Pinquart M. Associations of parenting dimensions and styles with externalizing problems of children and adolescents: An updated meta-analysis. Dev Psychol 2017;53(5):873-932. https://doi.org/10.1037/ dev0000295

65. Löfving-Gupta S, Lindbla F, Stickley A, et al. Community violence exposure and severe posttraumatic stress in suburban American youth: Risk and protective factors. Soc Psychiatry Psychiatr Epidemiol 2015;50(4):539-547. https://doi.org/10.1007/s00127-014-0965-2

66. Hammack PL, Richards MH, Luo Z, et al. Social support factors as moderators of community violence exposure among inner-city African American young adolescents. J Clin Child Adolesc Psychol 2004;33(3): 450-462. https://doi.org/10.1207/s15374424iccp3303 3

67. Copeland-Linder N, Lambert SF, Chen YF, et al. Contextual stress and health risk behaviors among African American adolescents. J Youth Adolesc 2011;40(2):158-173. https://doi.org/10.1007/s10964$010-9520-y$

68. D'Imperio RL, Dubow EF, Ippolito MF. Resilient and stress-affected adolescents in an urban setting. J Clin Child Psychol 2000;29(1):129-142. https://doi.org/10.1207/S15374424jccp2901_13

69. Humm A, Kaminer D, Hardy A. Social support, violence exposure and mental health among young South African adolescents. J Child Adolesc Ment Health 2018;30(1):41-50. https://doi.org/10.2989/172 80583.2018.1476358

70. Silberg J, Pickles A, Rutter M, et al. The influence of genetic factors and life stress on depression among adolescent girls. Arch Gen Psychiatry 1999;56(3):225-232. https://doi:10.1001/archpsyc.56.3.225

71. Abada T, Hou F, Ram B. The effects of harassment and victimization on self-rated health and mental health among Canadian adolescents. Soc Sci Med 2008;67(4):557-567. https://doi.org/10.1016/j. socscimed.2008.04.006

72. Foster ID, Kupermine GP, Price AW. Gender differences in posttraumatic stress and related symptoms among inner-city minority youth exposed to community violence. J Youth Adolesc 2004:33(1):59-69. https://doi.org/10.1023/A:1027386430859

73. Nolen-Hoeksema S, Girgus JS. The emergence of gender differences in depression during adolescence. Psychol Bull 1994;115(3):424-443. https://doi.org/10.1037/0033-2909.115.3.424

74. Scorgie F, Baron D, Stadler J, et al. From fear to resilience: Adolescents' experiences of violence in innercity Johannesburg, South Africa. BMC Public Health 2017;17(Suppl 3):51-64. https://doi.org/10.1186/ s12889-017-4349-x

75. Weissberg RP, Voyce CK, Kasprow WJ, et al. The Social and Health Assessment. New Haven, Conn.: Authors, 1991

76. Schwab-Stone M, Ayers TS, Kasprow W, et al. No safe haven: A study of violence exposure in an urban community. J Am Acad Child Adolesc Psychiatry 1995;34(10):1343-1352. https://doi. org/10.1097/00004583-199510000-00020

77. Schwab-Stone M, Chen C, Greenberger E, et al. No safe haven. II: The effects of violence exposure on urban youth. J Am Acad of Child Adolesc Psychiatry 1999;38(4):359-367. https://doi.org/10.1097/00004583199904000-00007

78. Achenbach T, Rescorla L. Manual for the ASEBA Adult Forms \& Profiles. Burlington, Vt: Research Center for Children, Youth, and Families, University of Vermont, 2003.

79. Ivanova MY, Achenbach T, Dumenci L, et al. Testing the 8-syndrome structure of the CBCL in 30 societies. J Clin Child Adolesc Psychol 2007;36(3):405-417. https://doi.org/10.1080/15374410701444363

80. Asanbe C, Moleko A, Visser M, et al. Parental HIV/AIDS and psychological health of younger children in South Africa. J Child Adolesc Ment Health 2016;28(2):175-185. https://doi.org/10.2989/17280583.2 016.1216853

81. Armsden GC, Greenberg MT. The inventory of parent and peer attachment: Individual differences and their relationship to psychological well-being in adolescence. J Youth Adolesc 1987;16(5):427-454. https://doi.org/10.1007/BF02202939

82. Jessor R, Jessor SL. Problem Behavior and Psychosocial Development: A Longitudinal Study of Youth. New York: Academic Press, 1977

83. Muthén LK, Muthén B. Mplus User's Guide. 6th ed. Los Angeles, Calif.: Muthén \& Muthén, 1998-2011.

84. Steiger JH. EzPath: A supplementary module for SYSTAT and SYSGRAPH. Evanston, Ill.: SYSTAT, 1989. 
85. Bentler PM. EQS 6.1 Structural Equations Program Manual. Encino, Calif.: Multivariate Software, 2004. 86. Hu L, Bentler PM. Fit indices in covariance structure modeling: Sensitivity to underparameterized model misspecification. Psychol Methods 1998;3(4):434-453. https://psycnet.apa.org/doi/10.1037/1082-
mons 989X.3.4.424

87. Louw KA, Ipser J, Phillips N, et al. Correlates of emotional and behavioural problems in children with perinatally acquired HIV in Cape Town, South Africa. AIDS Care 2016;28(7):842-850. https://doi.org/1 $0.1080 / 09540121.2016 .1140892$

88. Bandura A. Social Learning Theory. Englewood Cliffs, NJ: Prentice-Hall, 1977.

89. Guerra NG, Huesmann LR, Spindler A. Community violence exposure, social cognition, and (2003:74(5):1561-1567. hatpst/loi. org/10.1111/1467-8624.00623
90. Gaylord-Harden NK, Cunningham JA, Zelencik B. Effects of exposure to community violence on internalizing symptoms: Does desensitization to violence occur in African American youth? J Abnorm Child Psychol 2011;39(5):711-719. https://doi.org/10.1007/s10802-011-9510-x

91. Finkelhor D, Turner HA, Hamby SL, et al. Polyvictimization: Children's Exposure to Multiple Types of Violence, Crime and Abuse. Washington, DC: US Office of Juvenile Justice and Delinquency Prevention, 2011.

92. Finkelhor D, Ormrod RK, Turner HA, et al. Pathways to polyvictimization. Child Maltreat 2009;14(4):316-329. https://doi.org/10.1177/1077559509347012

Accepted 29 July 2019. 